\title{
Article
}

\section{Investigation of the Time Dependence of Wind-Induced Aeroelastic Response on a Scale Model of a High-Rise Building}

\author{
Fabio Rizzo
}

check for updates

Citation: Rizzo, F. Investigation of the Time Dependence of WindInduced Aeroelastic Response on a Scale Model of a High-Rise Building. Appl. Sci. 2021, 11, 3315. https:// doi.org/10.3390/app11083315

Academic Editors: Chiara Bedon, Flavio Stochino and Daniel Honfi

Received: 17 March 2021

Accepted: 29 March 2021

Published: 7 April 2021

Publisher's Note: MDPI stays neutral with regard to jurisdictional claims in published maps and institutional affiliations.

Copyright: (C) 2021 by the author. Licensee MDPI, Basel, Switzerland. This article is an open access article distributed under the terms and conditions of the Creative Commons Attribution (CC BY) license (https:// creativecommons.org/licenses/by/ $4.0 /)$.
Deapartmet of Engineering and Geology, Gabriele D’Annunzio University, viale Pindaro 42, 65013 Pescara, Italy; fabio.rizzo@unich.it

\begin{abstract}
Experimental wind tunnel test results are affected by acquisition times because extreme pressure peak statistics depend on the length of acquisition records. This is also true for dynamic tests on aeroelastic models where the structural response of the scale model is affected by aerodynamic damping and by random vortex shedding. This paper investigates the acquisition time dependence of linear transformation through singular value decomposition (SVD) and its correlation with floor accelerometric signals acquired during wind tunnel aeroelastic testing of a scale model high-rise building. Particular attention was given to the variability of eigenvectors, singular values and the correlation coefficient for two wind angles and thirteen different wind velocities. The cumulative distribution function of empirical magnitudes was fitted with numerical cumulative density function (CDF). Kolmogorov-Smirnov test results are also discussed.
\end{abstract}

Keywords: aeroelastic experiments; experimental uncertainty; singular value decomposition; correlation field

\section{Introduction}

Uncertainty related to experiments with scale models is an issue which is currently being discussed by the international scientific community. The reason for this is that codes of practice do not give experimental protocols [1,2] and that scientific literature focuses on specific cases. Error propagation due to the small scale of experimental models is known to affect results at the prototype scale [3-8].

The most common experimental errors can be grouped in three families: instrumental error, inaccuracy error and random repetitiveness error. Instrumental error is due to the limits of the instrument and is checked before the experiment is set up [3]. This is an awareness error and is commonly taken into account. Inaccuracy errors can be due to several aspects such as the inaccuracy of the model, inaccuracy when performing experiments and others. The small scale of the models [9] used for wind tunnel tests generally causes the most common inaccuracy errors. Small scales may cause loss of important details or undesired asymmetries or scaling inaccuracy due to the Reynolds number effects. However, the modern technology in the field of the 3D printer and control systems reduces the inaccuracy due to the model geometry. The situation for the Reynolds number effects is different because this is a long-standing problem that should be investigated by repeating tests many times.

The last family of experimental errors, random repetitiveness errors, is the hardest to check or to plan before experiments because it depends primarily on the amount of time and economic resources available for experiments. It is well known that the number of repetitions of experiments affects results at the prototype scale [3-5]. This is particularly relevant in the case of experiments that cannot be totally automated. Rizzo and Caracoglia (2018) [4] showed that the number of repetitions affects flutter critical velocity estimation during wind tunnel aeroelastic tests. Rizzo et al. (2020) [3] showed that the number of experiment repetitions affects dynamic identification of an aeroelastic model and consequently affects the prediction of magnitudes at the prototype scale. 
Acquisition time is another important aspect to take into account during dynamic experiments. Acquisition time in the wind tunnel is a relevant issue for both pressure and force tests and for aeroelastic tests. This dependence is discussed in literature with particular relevance to peak statistics. The maxima and minima of a random process depend on the recorded time history length. Most analytical models used to predict peak factors are affected by this aspect [10-20]. In the case of dynamic experiments, where structural response is affected by nonlinearity and vorticity, model vibration is related to acquisition time length even if recording processes in the wind tunnel are mostly stationary.

This paper discusses the acquisition time dependence of wind-induced floor acceleration on a scale model high-rise building. Individual values, eigenvectors and floor acceleration correlations between different levels and wind angles are assumed as significant magnitudes in order to have a measure of variability due to acquisition time length.

The complete recorded processes of floor accelerations at different levels of a high-rise building scale model were subdivided into random sub-processes. The variability of the singular values, eigenvectors and correlation coefficients is discussed.

Sections 2 and 3 discuss the structural setup of the prototype, the experimental model scaling and construction procedure and, finally, the wind tunnel aeroelastic tests. Section 4 discusses the acquisition time dependence of the individual values and of the wind induced floor acceleration correlation coefficient between both different levels of the building and different wind directions.

\section{Structural and the Experimental Setup}

The building being investigated is a 60-floor high-rise building with a cruciform plan inscribable in a $138.1 \times 138.1 \mathrm{~m}$ square. Total height is $300 \mathrm{~m}$, and the main structure is made of steel columns and reinforced concrete walls. Floors are made of truss steel structures, and slabs change their dimensions alternately from one floor to another. Structural elements were designed according to [1,2] through a finite element method (FEM) model illustrated in Figure 1a.

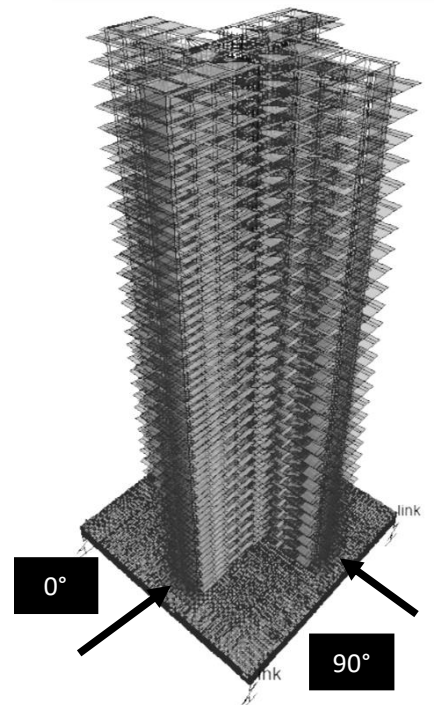

(a)

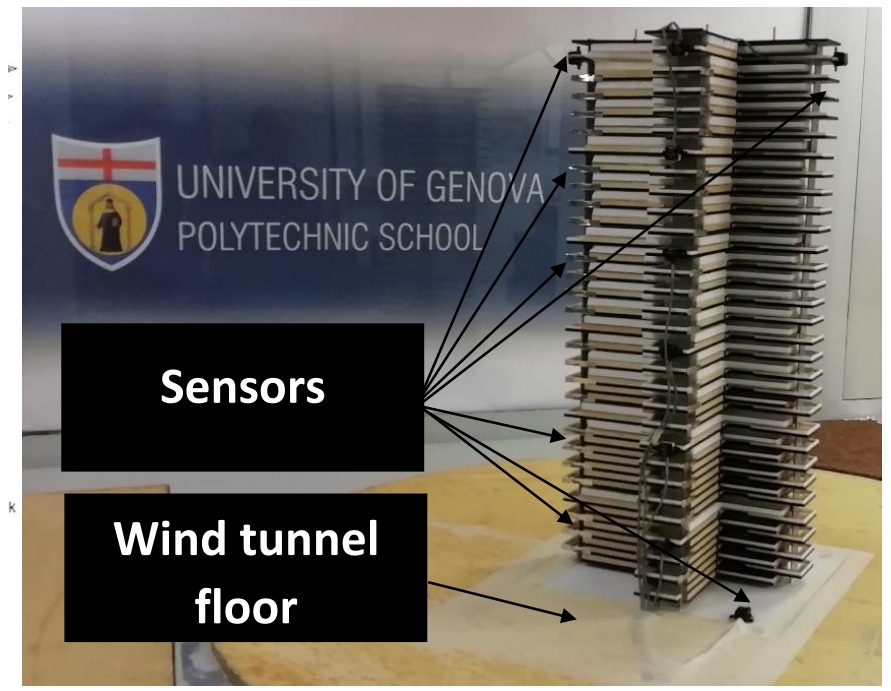

(b)

Figure 1. Structural (a) and experimental (b) setup.

The first two natural frequencies, estimated through modal analyses, are horizontal, along $X$ and $Y$, and equal to $0.12 \mathrm{~Hz}(\mathrm{Y})$ and $0.13 \mathrm{~Hz}(\mathrm{X})$. The structural damping ratio was assumed equal to $1.3 \%$. Estimated mean wind velocity at the top of the building, $v_{m}$ was $48.5 \mathrm{~m} / \mathrm{s}$ for $T_{R 0}=50$ years [1].

A scaled model to carry out aeroelastic wind tunnel experiments was designed and constructed according to the aeroelastic scaling procedure given by [9]. Velocity scale was 
calibrated to obtain a value of $5.9 \mathrm{~m} / \mathrm{s}$ (a prototype scale $48.5 \mathrm{~m} / \mathrm{s}$ considering the blockage correction) at the top of the model. The first natural frequency and mass were $5.86 \mathrm{~Hz}$ and $7.95 \mathrm{~kg}$. Scaling values are: $\lambda_{L}=2.50 \times 10^{-3}$ (a geometric scale of 1:400), $\lambda_{V}=0.12$ (velocity scale), $\lambda_{a}=5.93$ (acceleration scale), $\lambda_{\eta}=48.71$ (frequency scale), $\lambda_{m}=1.56 \cdot 10^{-8}$ (mass scale), $\lambda_{I, m}=9.76 \times 10^{-4}$ (inertia scale) and, finally, $\lambda_{t}=0.02$ (time scaling). The structural damping ratio was $1.3 \%$ for both prototype and model scale [10]. The scale model was made of steel and wood (Figure 1b). The floor slabs were made of $4 \mathrm{~mm}$ thick poplar wood. Four $2 \times 30 \times 750 \mathrm{~mm}$ steel plates were used to simulate walls and together with four $4 \mathrm{~mm}$ circular steel bars, located in the center of the wings were used to reproduce the total vertical load-bearing structure. The connection between slabs and walls is obtained through steel screws. Steel plates and bars are welded. The model mass is concentrated on six different points.

The first natural frequency and structural damping of the aeroelastic model were identified by experiments on the joint DIST-UNINA and ICD-CNR shaking table at the University of Napoli Federico II, Italy, laboratory. The first modal frequency, structural damping ratio and first modal shape were assessed [3,21,22].

\section{Wind Tunnel Experimental Results}

Aeroelastic testing was carried out at the DICCA laboratory at the University of Genoa, Italy. The DICCA wind tunnel is a closed-loop subsonic circuit tunnel with a cross-section of 1.70 (width) $\times 1.35$ (height) $\mathrm{m}$. A total of three different wind angles were investigated, $0^{\circ}$ (along wind), $45^{\circ}$ and $90^{\circ}$ (across wind), according to a suburban Terrain I velocity profile. Correction factors were used to take blockage effects into account. The factors ranged between 1.028 (for $0^{\circ}$ and $90^{\circ}$ ) and 1.04 (for $45^{\circ}$ ), [23] and were applied to the velocity and acceleration scale factors. Nine accelerometers monitored acceleration signals. Six accelerometers were located on six floors at $\mathrm{z} / \mathrm{H}=0.17,0.33,0.5,0.67,0.83$; one accelerometer was linked to the wind tunnel basement; and two accelerometers were located on the top floor of the model. A total of thirteen different velocities were tested, ranging from 5.4 to $112 \mathrm{~m} / \mathrm{s}$ at the building top at prototype scale.

Accelerations were measured at a sampling frequency of $1000 \mathrm{~Hz}$ for a time length of $180 \mathrm{~s}$. At the prototype scale, this corresponds to a time step of $0.05 \mathrm{~s}$ and a time length of $9000 \mathrm{~s}$.

The entire process, to investigate the variability of magnitudes such as singular values or eigenvectors, was subdivided into fifteen $10 \mathrm{~min}$ long recording sessions [24-29]. Figure 2 shows two examples of processes with $U=49.0 \mathrm{~m} / \mathrm{s}$, along and across wind, subdivided in sub-processes. The along versus across wind acceleration point cloud graph shown in Figure 3 shows that the difference between sub-processes (in the $10 \mathrm{~min}$ records) is relevant because it changes significantly as for example with $\mathrm{T}$ [0; 9000] (Figure 3c), $\mathrm{T}$ [2400; 3000] (Figure 3d), T [7200; 7800] (Figure 3e) and T [840; 9000] (Figure 3f) [24-29].

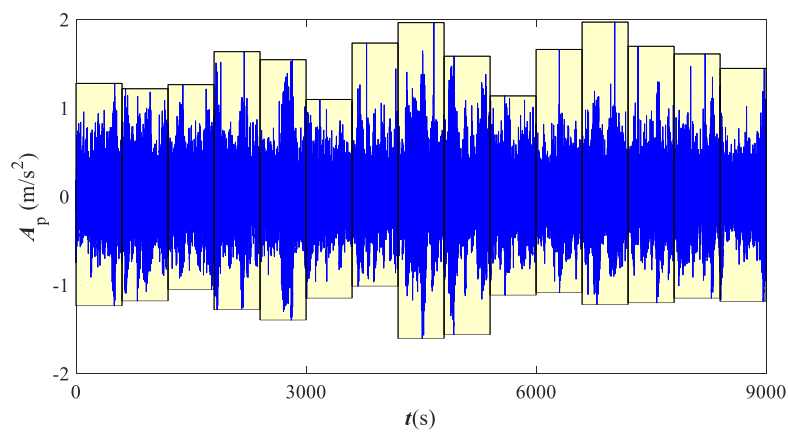

(a)

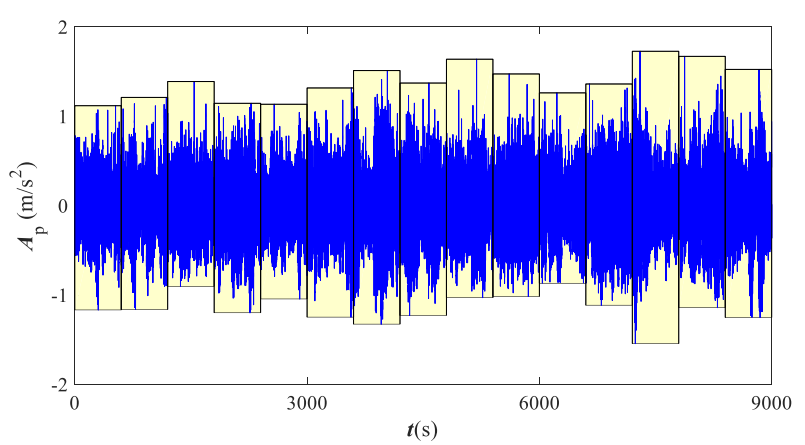

(b)

Figure 2. Ten minute accelerometric signal records at the building top with $U=49.0 \mathrm{~m} / \mathrm{s}$, along wind $\left(0^{\circ}\right)($ a) and across wind $\left(90^{\circ}\right)(\mathbf{b})$. 

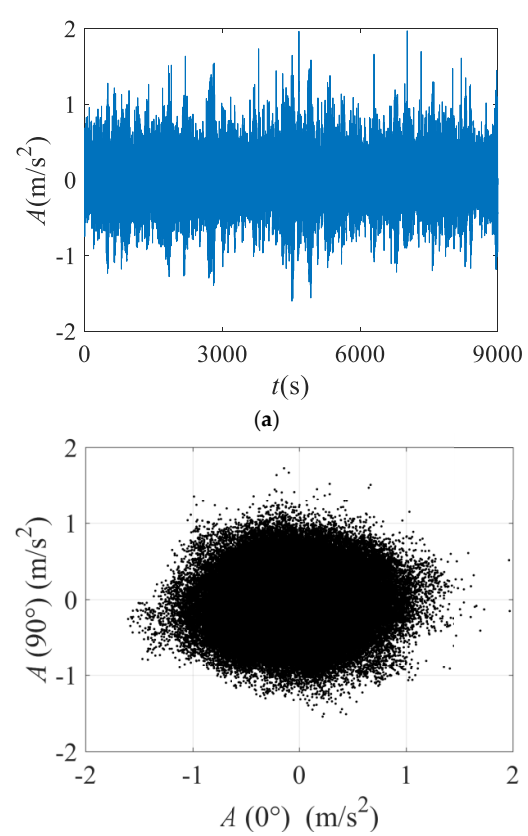

(c)

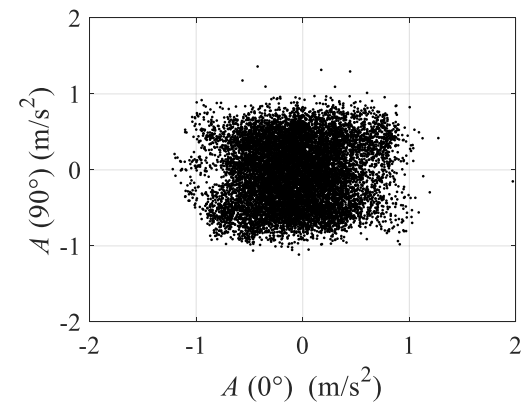

(e)
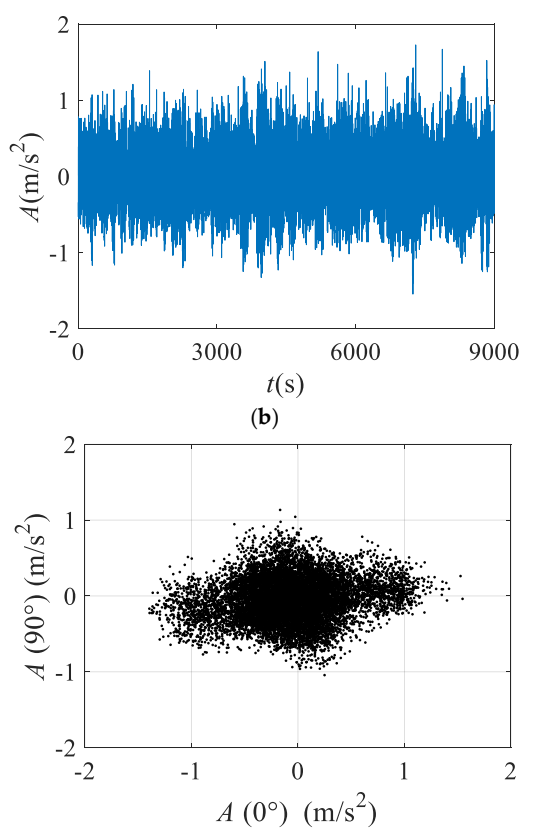

(d)

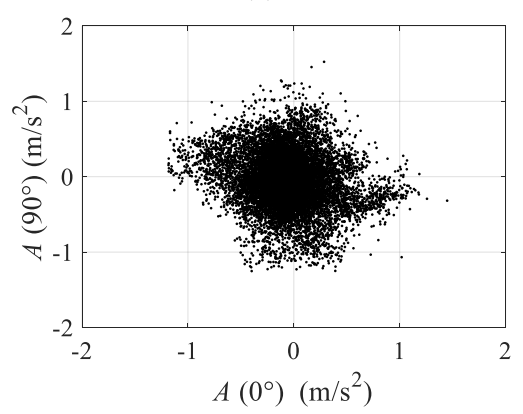

(f)

Figure 3. Building top acceleration signal with $U=49.0 \mathrm{~m} / \mathrm{s}$, along wind (a), across wind (b), along wind versus across wind with T [0; 9000] (c), T [2400; 3000] (d), T [7200; 7800] (e), T [840; 9000] (f).

\section{Time Dependence of Wind Induced Floor Acceleration}

\subsection{Singular Value Decomposition}

In linear algebra, the singular value decomposition (SVD) of a matrix is a factorization of that matrix into three matrices. This value has some interesting algebraic properties and conveys important geometrical and theoretical insights about linear transformations. It also has some important applications in data science [30]. Singular value decomposition takes a rectangular matrix of gene expression data (defined as $A$, where $A$ is a $n \times p$ matrix) in which the $n$ rows represent the genes, and the $p$ columns represent the experimental conditions. The SVD theorem states:

$$
A_{n \times p}=U_{n \times n} \times S_{n \times p} \times V_{p \times p}^{T}
$$

where the $U_{n \times n}$ columns are the left singular vectors (gene coefficient vectors); $S_{n \times p}$ (the same dimensions as A) has singular values and is diagonal (mode amplitudes); and $V_{p \times p}^{T}$ has rows that are the right singular vectors (expression level vectors). The SVD represents an expansion of the original data in a coordinate system where the covariance matrix is diagonal. Calculating the SVD consists in finding the eigenvalues and eigenvectors of $A_{n \times p} \times A_{n \times p}^{T}$ and $A_{n \times p}^{T} \times A_{n \times p}$. The eigenvectors of $A_{n \times p}^{T} \times A_{n \times p}$ make up the columns of $V_{p \times p}$; the eigenvectors of $A_{n \times p} \times A_{n \times p}^{T}$ make up the columns of $U_{n \times p}$. The singular values in $S_{n \times p}$ are also square roots of eigenvalues from $A_{n \times p} \times A_{n \times p}^{T}$ or $A_{n \times p}^{T} \times A_{n \times p}$. The singular values are the diagonal entries of the $S_{n \times p}$ matrix and 
are arranged in descending order. The singular values are always real numbers. If matrix $A_{n \times p}$ is a real matrix, then $U_{n \times n}$ and $V_{p \times p}$ are also real.

The singular value decomposition of the $A_{180000 \times 6}$ acceleration matrix was estimated for two different wind angles, $0^{\circ}$ and $90^{\circ}$, respectively along and across wind, and thirteen different wind velocities, in order to examine the variability of $V_{6 \times 6}$ and the diagonal of $S_{180000 \times 6}$ computed for different 10 min records.

\subsubsection{Singular Value Variability}

The diagonal of $S_{180000 \times 6}$ was estimated for each fifteen $10 \mathrm{~min}$ record of the wind induced floor accelerations. Figure 4 shows the diagonal of $S_{180000 \times 6} \times$ variability along wind and across wind for three significate velocities at the building top: a small velocity, $U=5.4 \mathrm{~m} / \mathrm{s}$; the estimated by CNR DT 207, 2018 velocity, $U=49.0 \mathrm{~m} / \mathrm{s}$; and a very large velocity, $U=111.8 \mathrm{~m} / \mathrm{s}$.
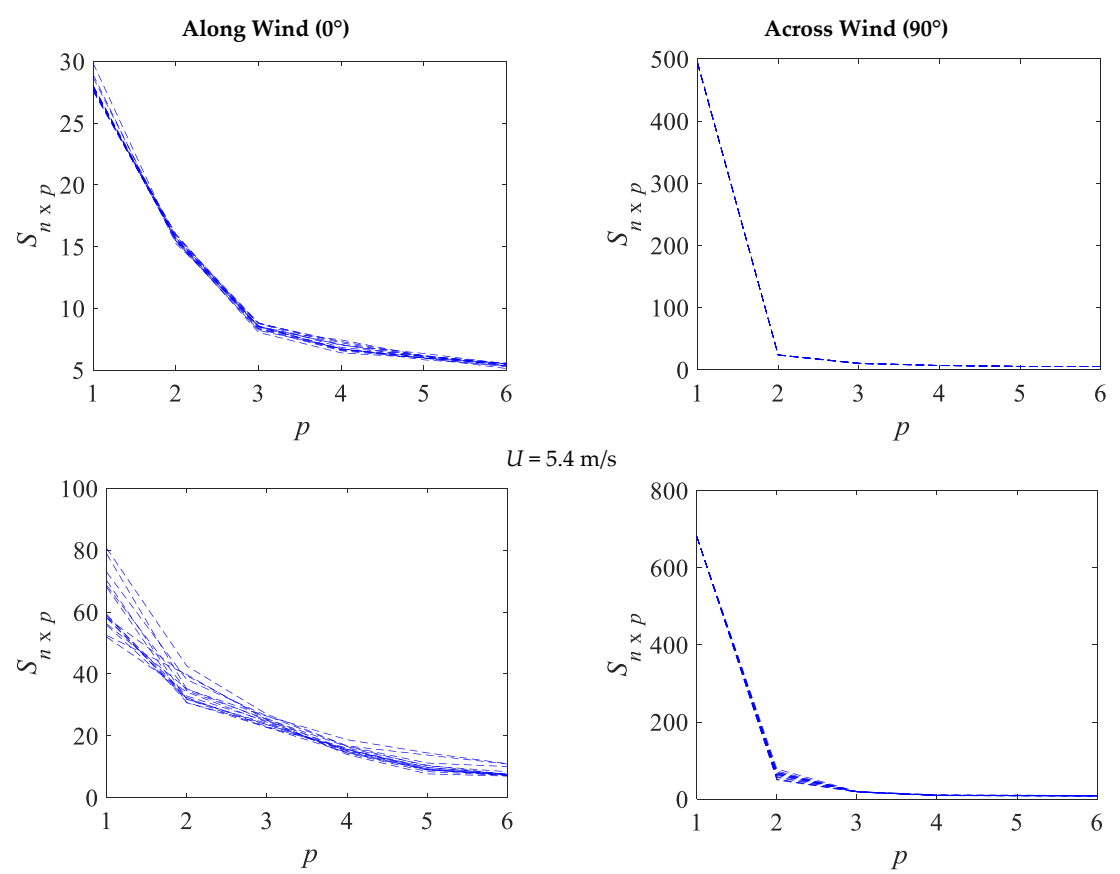

$U=5.4 \mathrm{~m} / \mathrm{s}$
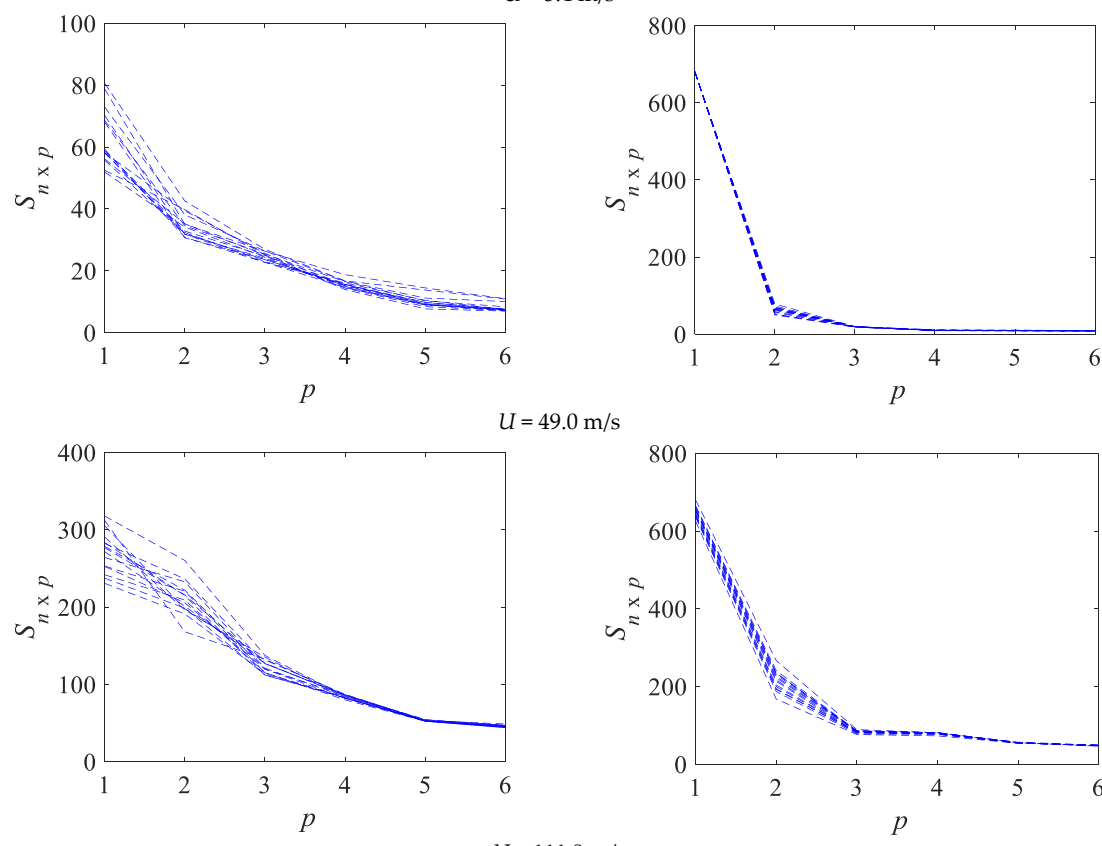

$U=49.0 \mathrm{~m} / \mathrm{s}$

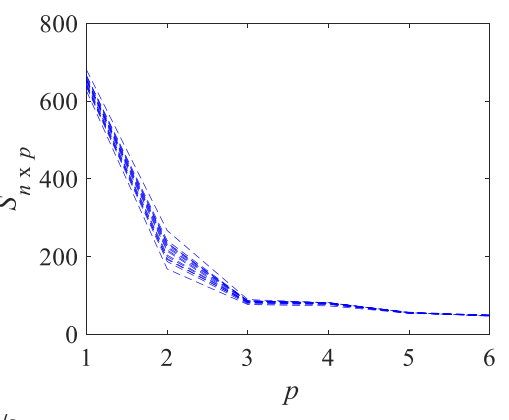

Figure 4. Variability of the singular values $S_{n \times p}$ with different velocities.

Figure 4 shows that the variability is significant for the first three modes (i.e., $p=1$, 2 and 3) and along wind. Variability increases when velocities increase and is much smaller across wind. This suggests that the across wind singular values are not affected by the random nature of the wind flow. Along wind, by contrast, the singular values significantly depend on the recorded records. They vary up to $40 \%$ for the highest velocity. It is very important to specify that the estimated modes through the Property Orthogonal Decomposition (POD) methodology and their discussion only refer to the experimental model. The experimental model was calibrated only on the first mode of the prototype, and 
for this reason, there is no reliable correspondence for modes higher than the first between the test model and the prototype structure. However, the paper goal is to investigate and to discuss the variability of the test model modes as a function of acquisition time length, and for this reason, the discussion on the higher modes is being reported.

\subsubsection{Eigenvector Variability}

Eigenvectors were estimated along and across wind with different velocities and for each 10-min record in order to examine the variability at each level (levels from 1 to 6, from base to top). Figure 5 shows the first three eigenvectors along wind (Figure $5 \mathrm{a}$ ) and across wind (Figure 5b) variability. Different curves overlapping in Figure 5 represent the eigenvector shape for each subinterval. It was observed that the first mode is very similar for both oscillation directions, whereas modes 2 and 3 are quite different between along wind and across wind. The eigenvector variability increases for the first modes for both along wind and across wind, and it increases with increasing velocities as is illustrated in Figure 6 for both oscillation directions. In addition, eigenvectors have a trend which is quite different with increasing velocities. This result seems significant because it means that eigenvector trends are affected by the randomness of the wind flow, and consequently, their variability should be taken into account.

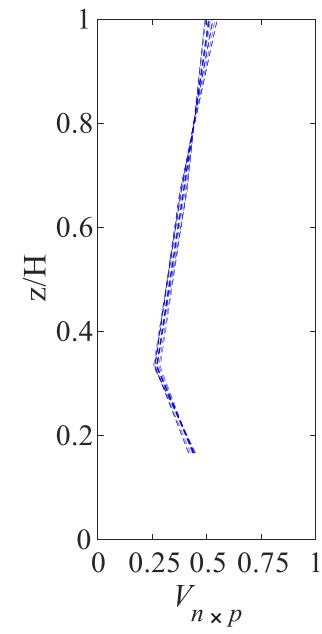

Mode \#1

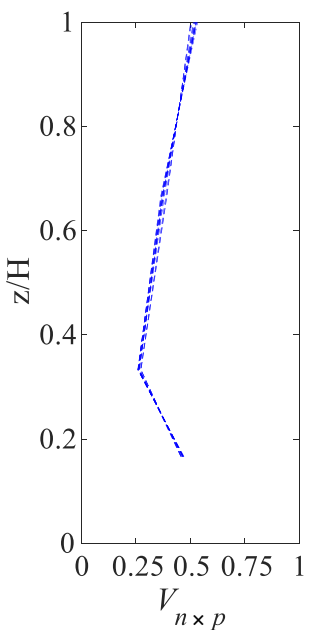

Mode \#1

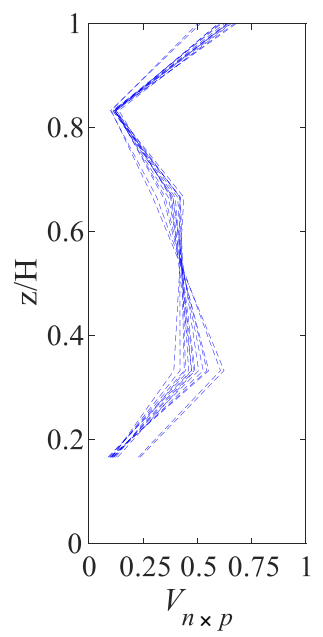

Mode \#2

(a)

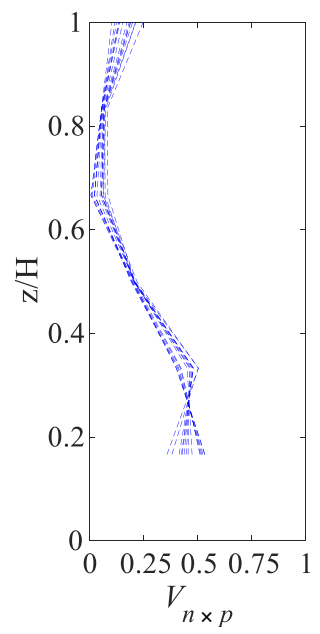

(b)

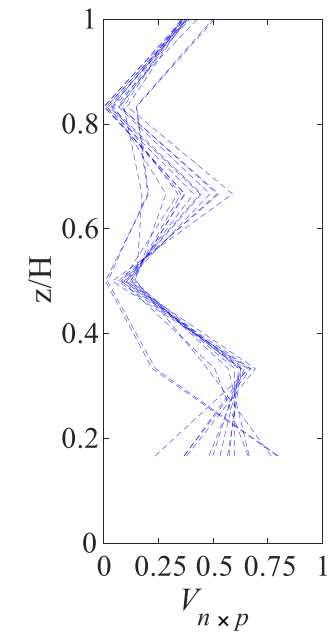

Mode \#3

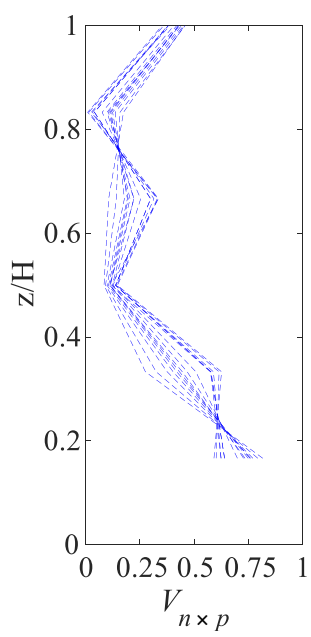

Mode \#3

Figure 5. Eigenvectors along wind (a) and across wind (b) variability with $U=49.0 \mathrm{~m} / \mathrm{s}$. 


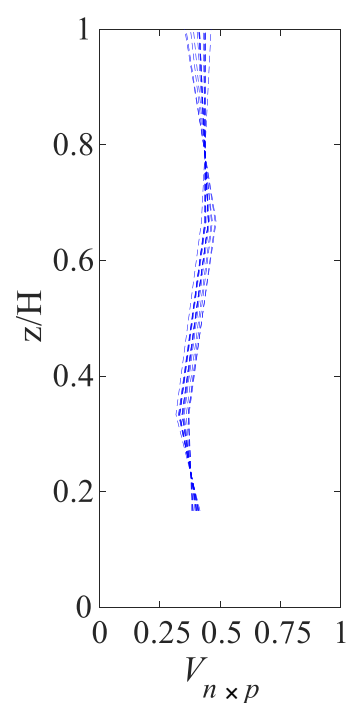

$U=40.2 \mathrm{~m} / \mathrm{s}$

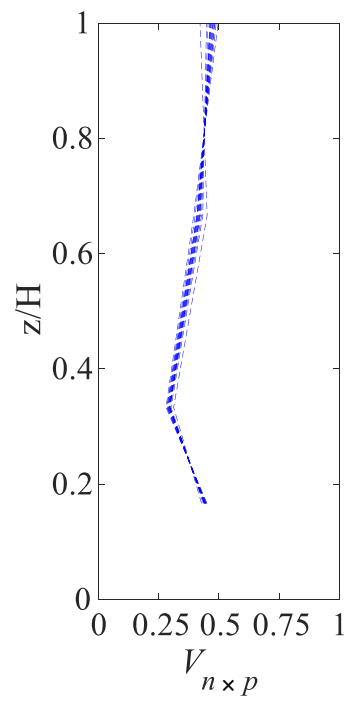

$U=40.2 \mathrm{~m} / \mathrm{s}$

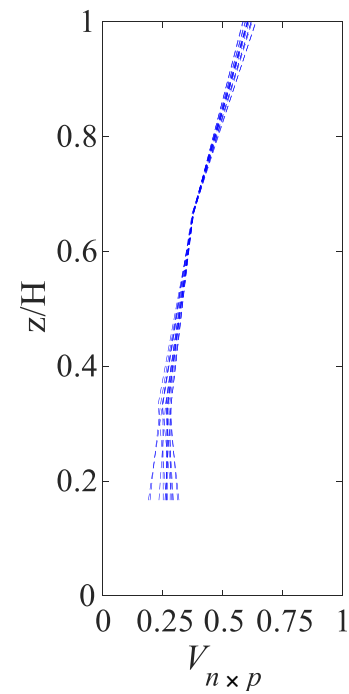

$U=67.3 \mathrm{~m} / \mathrm{s}$

(a)

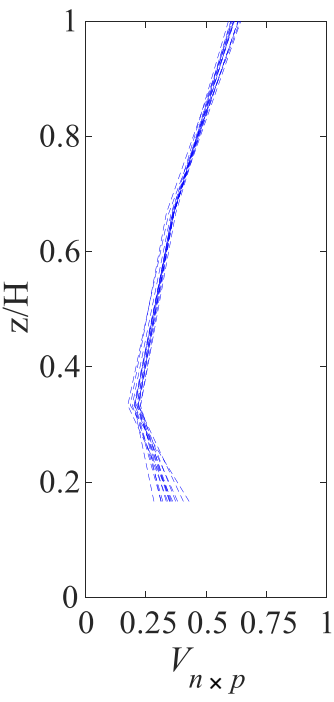

$U=67.3 \mathrm{~m} / \mathrm{s}$

(b)

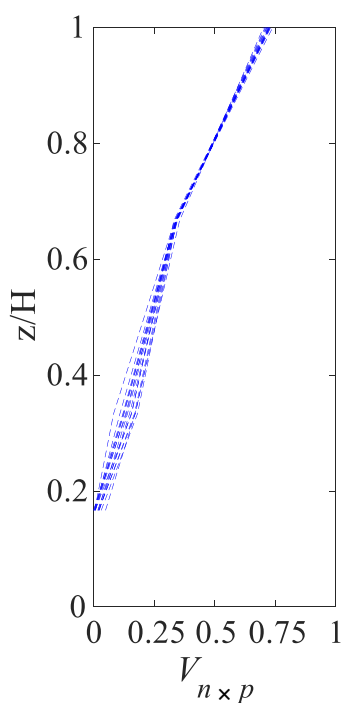

$U=93.3 \mathrm{~m} / \mathrm{s}$

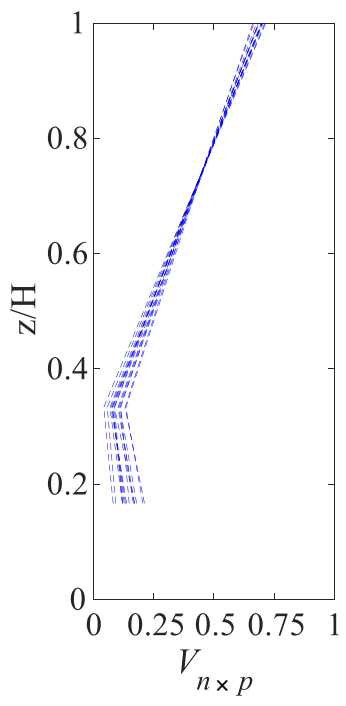

$U=93.3 \mathrm{~m} / \mathrm{s}$

Figure 6. Eigenvector \#1 along wind (a) and across wind (b) variability as a function of the wind velocity.

The eigenvectors were calculated for each subinterval (i.e., fifteen), for each wind velocity (i.e., thirteen), and for each investigated building level (i.e., six). The standard deviation of eigenvector \#1 for different subintervals has been plotted as a function of the wind velocity and building floor in Figure 7 . Figure 7 shows the three-dimensional variability of the standard deviation of the eigenvectors for Mode \#1 along (Figure 7a) and across (Figure $7 \mathrm{~b}$ ) wind. The standard deviation is much larger along wind than across wind for all wind velocities tested, confirming the variability shown in Figures 5 and 6.

The empirical cumulative density function (CDF) of the fifteen different values was estimated for each building level wind velocity and wind angle to give a measure of the probabilistic trends of the eigenvectors. The empirical CDF and numerical CDF are not the same distribution. The Kolmogorov-Smirnov (K-S) test was repeated by varying significance levels from $5 \%$ to $50 \%$, and similar results were obtained. The best fitting, in any case, is given by the Generalized extreme value distribution (GEV) distribution even though it is not satisfactory. 


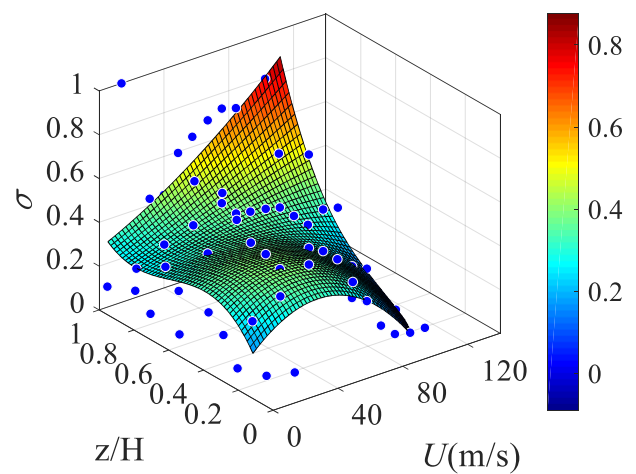

(a)

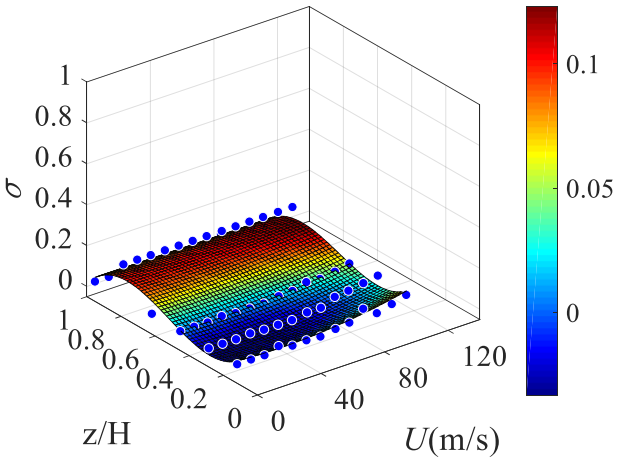

(b)

Figure 7. Standard deviation variation for Mode \#1 along wind (a) and across wind (b).

Figure 8 shows some examples. The empirical CDF was fitted through numerical CDF as the Normal, Gamma, Weibull, GEV and Gumbel distribution CDF. The two-sample Kolmogorov-Smirnov (K-S) [31] test was carried out to look for the best fitting. The KS test did not reject (i.e., failed to reject) the null hypothesis of inequality at the $5 \%$ significance level.

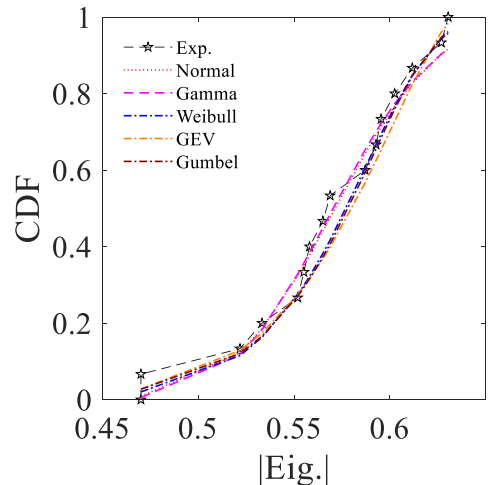

(a)

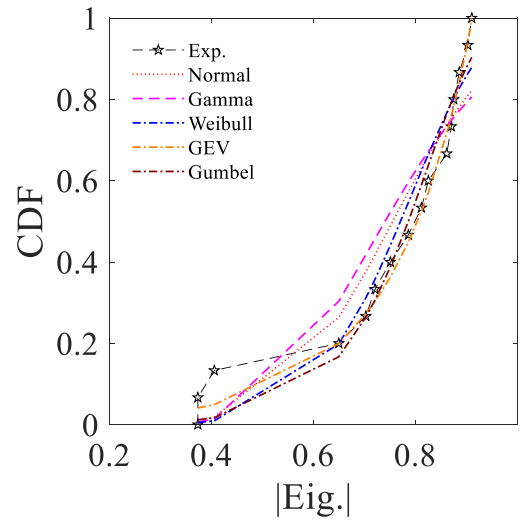

(c)

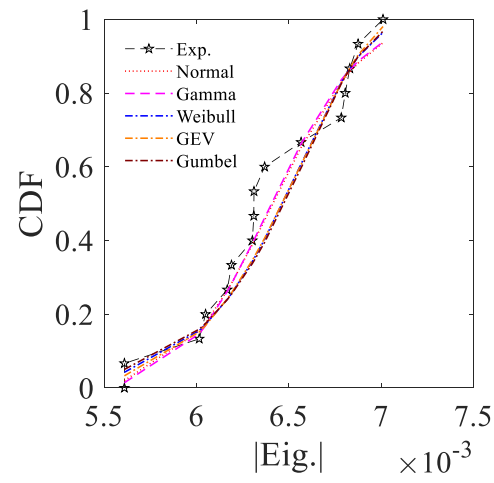

(b)

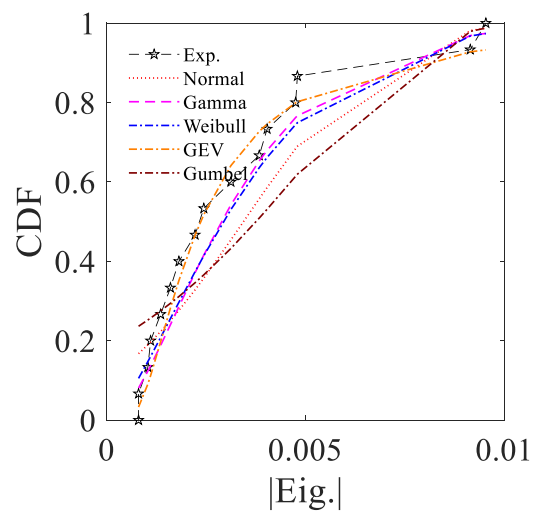

(d)

Figure 8. Cumulative density function (CDF) of Mode $\# 1$ and $\mathrm{z} / \mathrm{H}=1$ of the eigenvector with $U=49.0$ along wind (a) and across wind (b) and $111.8 \mathrm{~m} / \mathrm{s}$ along wind (c) and across wind (d).

\subsection{Time Dependence of the Floor Acceleration Correlation Coefficient}

The space correlation of two random processes is usually taken as a measure of how much one variable is related to another variable. In the case of a high-rise building, the correlation of floor acceleration at different building levels is a measure of the effects of aerodynamics, such as vortex shedding, and aeroelastics, such as nonlinear structural movements. 
A further attempt was made to calculate a measure of response variability due to different acquisition records, examining the correlation coefficients $\rho_{(6,1 \ldots 5)}$ between the signal on the top, level \#6 and on the other five levels, \#1, \#2, \#3, \#4 and \#5, corresponding to $\mathrm{z} / \mathrm{H}=1 / 6,2 / 6,3 / 6,4 / 6$ and $5 / 6$, for each 10 min recording session.

Figure 9 shows the variability of the correlation coefficient $\rho_{(6,1 \ldots 5)}$ estimated for fifteen $10 \mathrm{~min}$ recording sessions with two significant velocities $(U=49.0 \mathrm{~m} / \mathrm{s}$ and $111.8 \mathrm{~m} / \mathrm{s})$ and two wind angles $\left(0^{\circ}\right.$ and $\left.90^{\circ}\right)$. The variability of $\rho$ ranges from $5 \%$ to $75 \%$ and consequently is non-negligible. Its variability is larger along wind (Figure 9a) than across wind (Figure 9b) and increases with increases in velocity.

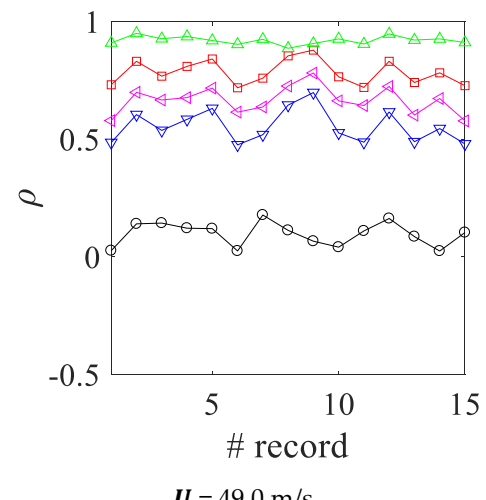

$\boldsymbol{U}=49.0 \mathrm{~m} / \mathrm{s}$

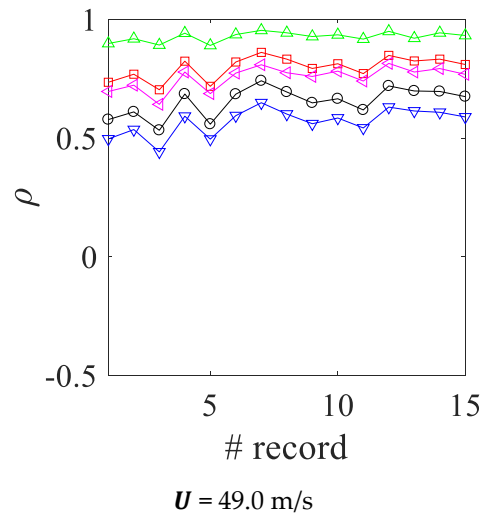

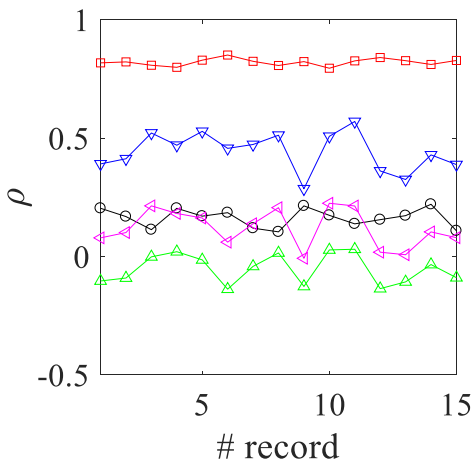

$\boldsymbol{U}=111.8 \mathrm{~m} / \mathrm{s}$

(a)

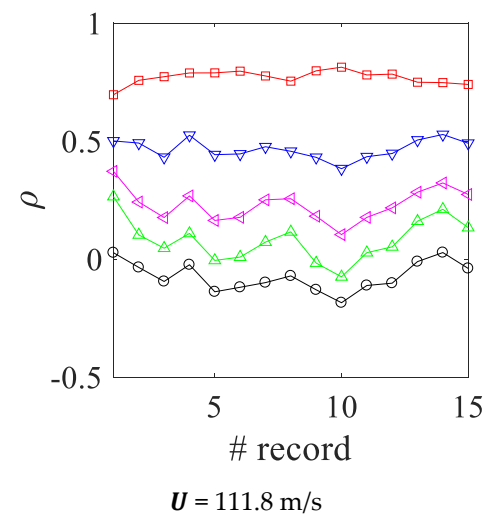

legend

- \#6 vs \#5

$\square-\# 6$ vs \#4

$\nabla-\# 6$ vs \#3

$\triangleleft-\# 6$ vs \#2

$\triangle$ \#6 vs \#1

(b)

Figure 9. Variability of the correlation coefficient from the building top (i.e., level \#6) to levels \#1, \#2, $\# 3$, \#4 and \#5 along wind (a) and across wind (b).

It can be seen that the best along wind correlation for all velocities was calculated between levels \#6 and \#1, while the best across wind correlation was between levels \#6 and \#4. The correlation between two adjoining intermediate floors is quite low for all velocities and wind directions. This seems to suggest that along wind aerodynamics, in the range between $\mathrm{z} / \mathrm{H}=0.33$ and $\mathrm{z} / \mathrm{H}=0.83$, gives significant vorticity that induces a structural vibration different from that at the top. This effect is probably due to the not slender shape of the building, to the slabs and to the free vibration associated with the first structural modal shape which, in this case, is not a pendulum motion like that of a simple harmonic oscillator.

The standard deviation of the $\rho$ coefficient estimated for all fifteen along and across wind short (10 $\mathrm{min}$ ) records ranges between 0.01 and 0.1 as shown in Figure 10. Figure 10 shows that the standard deviation, and consequently $\rho$ variability, depends on flow velocity and on floor position. Values for the correlation between levels \#6 and \#5 along wind seem anomalous because the correlation is very small. It is reasonable to think that acquisitions were affected by noise during tests. The difference between small and large velocities is relevant but not the same for all levels. The three-dimensional trend shows a valley around 
$\mathrm{z} / \mathrm{H}=0.5$ for all velocities and two peaks at the top and close to the base for the highest velocities. This irregular trend of the standard deviation as a function of wind velocity and height above ground confirms that structural vibration is very different between the top and the other levels and also that the correlation coefficient is affected by the randomness of the wind flow distribution, consequently varying significantly from one time interval to another.

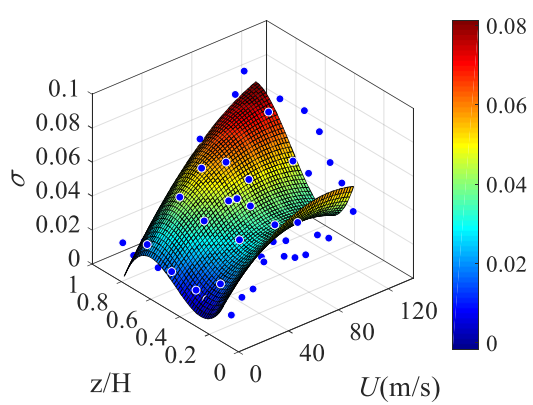

(a)

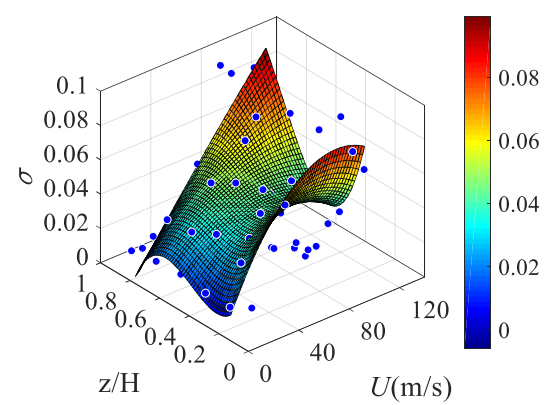

(b)

Figure 10. Standard deviation variation of $\rho_{(6,1 \ldots 5)}$, along wind (a) and across wind (b).

The correlation coefficient between along and across wind floor acceleration was estimated, and its variability shown in Figure 11a for two significant velocities, $U=49.0 \mathrm{~m} / \mathrm{s}$ and $111.8 \mathrm{~m} / \mathrm{s}$. It can be seen that the variability is slightly larger for $U=49 \mathrm{~m} / \mathrm{s}$ than $U=111.8 \mathrm{~m} / \mathrm{s}$. This effect is evidenced in Figure $11 \mathrm{~b}$ that shows the three-dimensional trend of the standard deviation of the correlation coefficient for the fifteen records as a function of wind velocity and building levels. It was observed in the range from 40 to $80 \mathrm{~m} / \mathrm{s}$. It is reasonable to think that in the range from $40 \mathrm{~m} / \mathrm{s}$ to $80 \mathrm{~m} / \mathrm{s}$, a resonance between oscillation along wind and across wind occurs, although this aspect should be carefully investigated through additional tests.

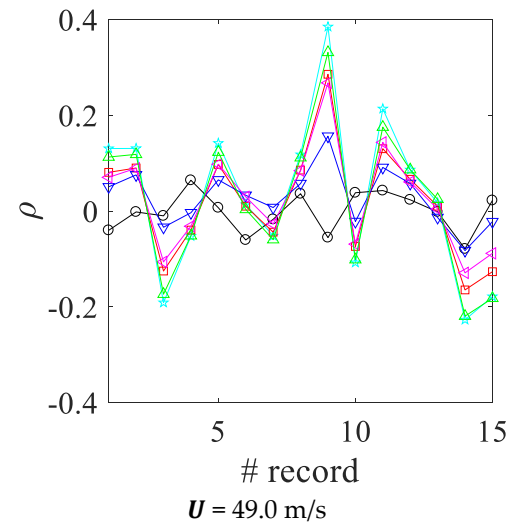

(a)

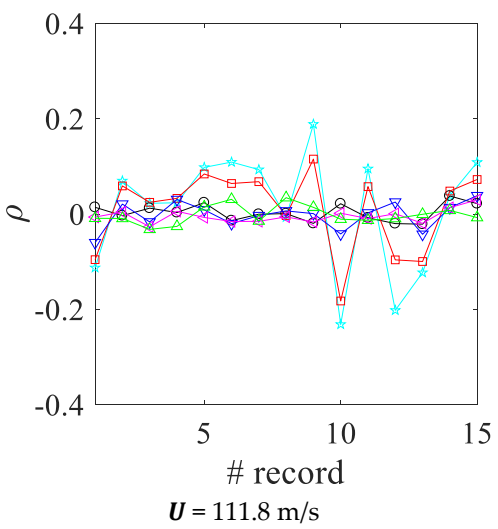

legend

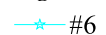

$-\# 5$

$\nabla 3$
$\triangleleft-\# 2$

$\triangle \# 1$

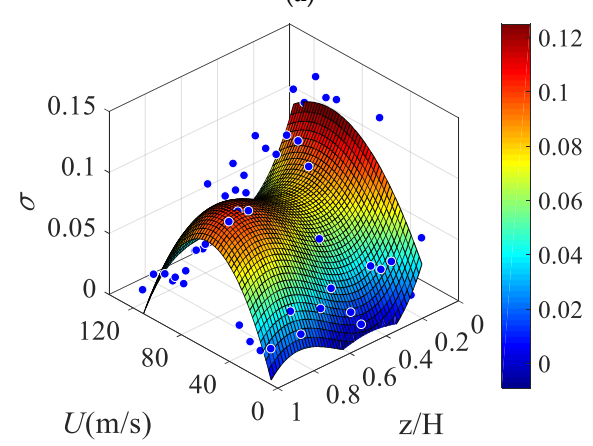

(b)

Figure 11. Variability of the correlation coefficient at different levels between along and across wind (a) and the standard deviation as a function of wind velocity and building levels (b). 
The standard deviation ranges from 0.01 to 0.15 , taking its maximum value at low wind velocity levels, in the range from $40 \mathrm{~m} / \mathrm{s}$ to $80 \mathrm{~m} / \mathrm{s}$. Figure 12 shows the CDF of the correlation coefficient estimated between level \#6 and levels from \#1 to \#5. Figure 12 shows that, for $U=49.0 \mathrm{~m} / \mathrm{s}$, the GEV distribution gives the best fitting of the empirical CDF even if, as with the eigenvectors, the KS tests accepted the null hypothesis of inequality for all numerical CDFs.

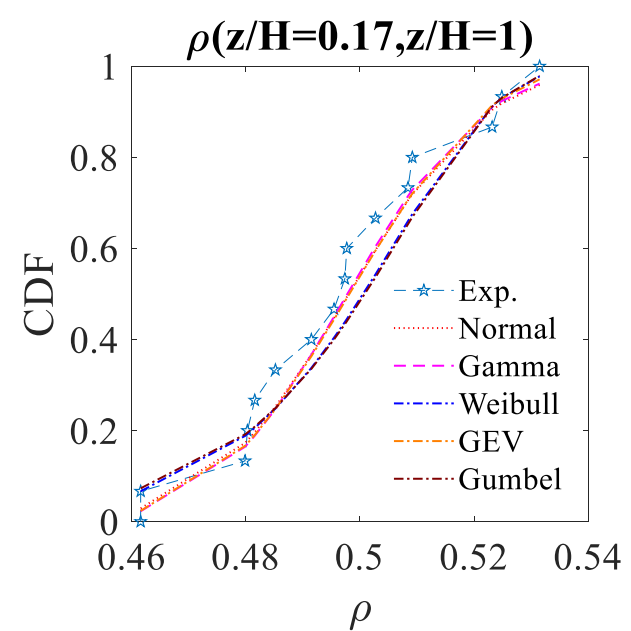

(a)

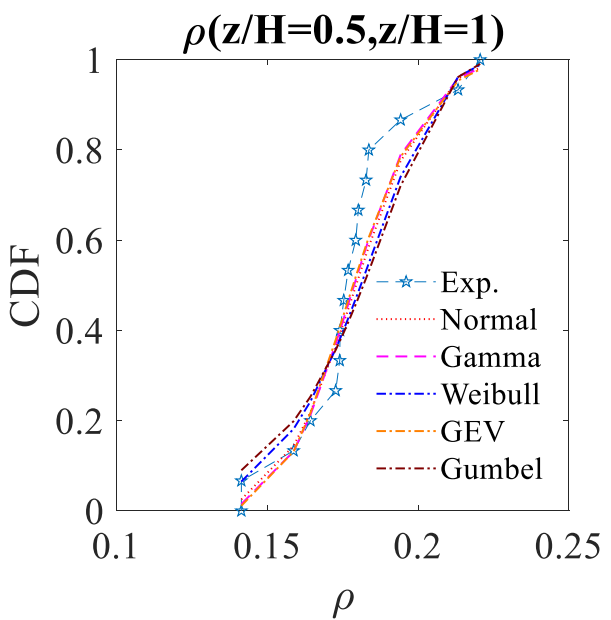

(c)

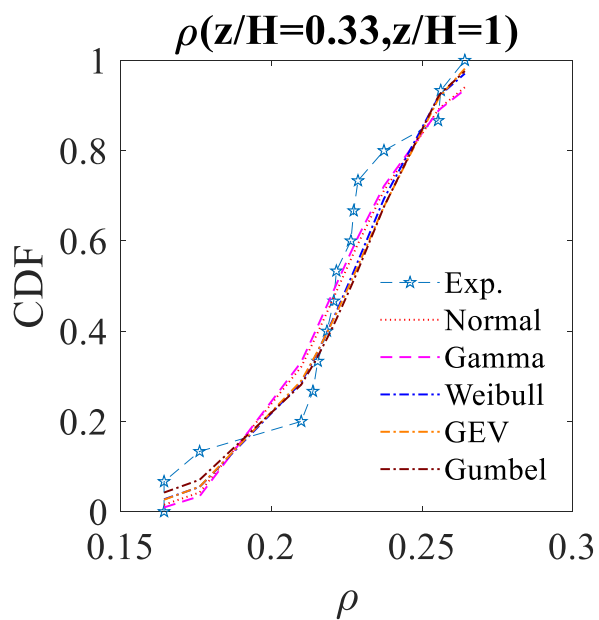

(b)

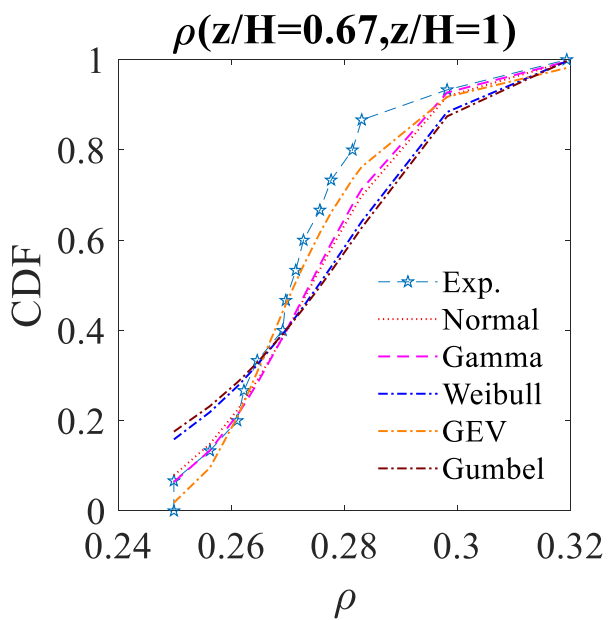

(d)

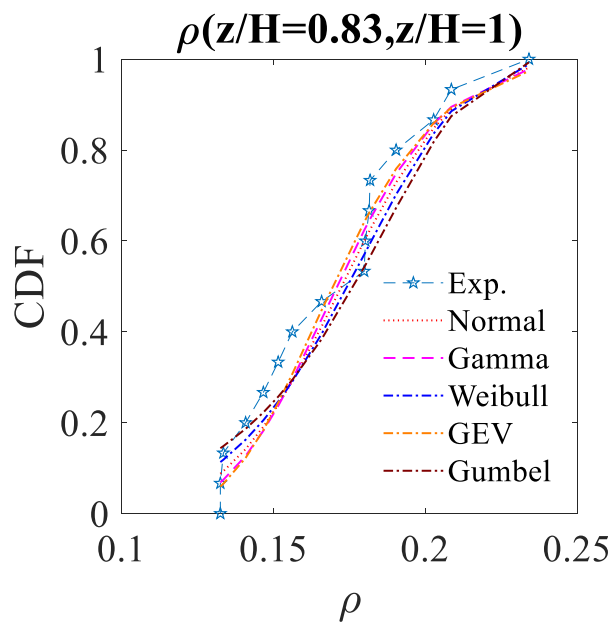

(e)

Figure 12. CDF of the correlation coefficient $r$ between level \#6 and (a) level \#1 (b) level \#2 (c) level \#3; (d) level \#4; and (e) level \#5; along wind with $U=49 \mathrm{~m} / \mathrm{s}$. 


\section{Conclusions}

Acquisition time dependence of significant magnitudes, such as singular values, eigenvectors and correlation coefficients of wind-induced floor accelerometric signals acquired on a scale model of a high-rise building, is discussed by examining their variability from one time interval to another.

The entire wind tunnel data acquisition process was subdivided into fifteen $10 \mathrm{~min}$ recording sessions.

The SVD was calculated for two wind angles, along and across wind, and for thirteen wind velocities for all recording sessions. It was found that variability of the singular value increases when the wind velocity increases and that there is a significant difference between along and across wind values. Across wind variability is much smaller than along wind. The same trend was noted for the eigenvectors. The probability density function (CDF) of the eigenvectors for different velocities and at different levels was fitted through numerical CDF. It was found that the GEV distribution gave the best fitting even if it was not satisfactory according to the Kolmogorov-Smirnov test. The three-dimensional trend of standard deviation as a function of building levels and wind velocities shows that the variability of the eigenvectors assumes its maximum along wind value at the building top and for the highest velocities.

Likewise, the correlation coefficient between the top and the other levels was calculated, and its variability for the fifteen $10 \mathrm{~min}$ recording sessions was investigated. It was found that these values are closely affected by the randomness of the flow because it varies significantly from one time interval to another. The correlation coefficient at the building top between along and across wind measurements was calculated and was found to vary slightly more for velocities in the range from $40 \mathrm{~m} / \mathrm{s}$ to $80 \mathrm{~m} / \mathrm{s}$ and for low levels.

The results discussed here show that uncertainty due to the randomness of wind tunnel wind flow affects structural response during aeroelastic tests. The dependence of results from the acquisition time length was confirmed and nonnegligible variability was observed. In particular, it was observed that the variability of the eigenvectors under wind increases with the wind velocity and distant from the ground along wind, whereas this trend flattens across wind. This uncertainty should be taken into account during experiments and output processing, examining the cumulative probability trends and assuming a reliable level of confidence for the estimated crucial magnitudes, such as the modal shapes, frequencies and damping ratio.

Funding: This research was supported by the Italian Ministry of Education.

Data Availability Statement: The data used to support this research are available from the corresponding author upon request.

Acknowledgments: The Author thanks Andrea Freda and Giuseppe Piccardo for their significant support during the experimentation sessions in the DICCA Wind Tunnel of the University of Genoa and Giuseppe Maddaloni, University of Sannio (Benevento), for his support during shaking table experiments. He is also grateful to Davide Perazzetti for his support during the model construction and to the company H-Sign srl for its support of this research.

Conflicts of Interest: The author declares no conflict of interest.

\section{References}

1. CNR (National Research Council of Italy). Guide for the Assessment of Wind Actions and Effects on Structures; CNR-DT 207/2008; CNR: Rome, Italy, 2008.

2. CEN (Comité Européen de Normalization). Eurocode 1: Actions on Structures—Part 1-4: General Actions—Wind Actions; EN-1991-14; CEN: Brussels, Belgium, 2005.

3. Rizzo, F.; Ricciardelli, F.; Maddaloni, G.; Bonati, A.; Occhiuzzi, A. Experimental error analysis of dynamic properties for a reduced-scale high-rise building model and implications on full-scale behaviour. J. Build. Eng. 2020, 28, 101067. [CrossRef]

4. Rizzo, F.; Caracoglia, L. Examining wind tunnel errors in Scanlan derivatives and flutter speed of a closed-box. J. Wind Struct. 2018, 26, 231-251. 
5. Rizzo, F.; Caracoglia, L.; Montelpare, S. Predicting the flutter speed of a pedestrian suspension bridge through examination of laboratory experimental errors. Eng. Struct. 2018, 172, 589-613. [CrossRef]

6. Desceliers, C.; Soize, C.; Ghanem, R. Identification of chaos representations of elastic properties of random media using experimental vibration tests. Comput. Mech. 2007, 36, 831-838. [CrossRef]

7. Schoefs, F.; Yáñez-Godoy, H.; Lanata, F. Polynomial chaos representation for identification of mechanical characteristics of instrumented structures. Comput. Aided Civ. Infrastruct. 2011, 26, 173-189. [CrossRef]

8. Seo, D.W.; Caracoglia, L. Derivation of equivalent gust effect factors for wind loading on low-rise buildings through DatabaseAssisted-Design approach. Eng. Struct. 2010, 32, 328-336. [CrossRef]

9. Isyumov, N. The Aeroelastic Modelling of Tall Buildings. In Proceedings of the International Workshop on Wind Tunnel Modelling Criteria and Technique in Civil Engineering Applications, Gaithersburg, MD, USA, April 1982; Timothy, A.R., Ed.; Cambridge University Press: Cambridge, UK, 1982.

10. Huang, M.; Huang, C.M.; Chan, C.M.; ChanWen-juan, L.; Chung-Siu, K. Statistical extremes and peak factors in wind-induced vibration of tall buildings. J. Zhejiang Univ. Sci. A Appl. Phys. Eng. 2012, 13, 18-32. [CrossRef]

11. Huang, M.F.; Lou, W.; Chan, C.M.; Lin, N.; Pan, X. Peak distributions and peak factors of wind-induced pressure processes on tall buildings. J. Eng. Mech. 2013, 139, 1744-1756. [CrossRef]

12. Huang, M.F.; Huang, S.; Feng, H.; Lou, W.J. Non-Gaussian time-dependent statistics of wind pressure processes on a roof structure. Wind Struct. 2016, 23, 275-300. [CrossRef]

13. Huang, G.; Luo, Y.; Gurley, K.R.; Ding Ying Luo, J. Revisiting moment-based characterization for wind pressures. J. Wind Eng. Ind. Aerodyn. 2016, 151, 158-168. [CrossRef]

14. Huang, G.; Luo, Y.; Gurley, K.R.; Ding Ying Luo, J. Response to Revisiting moment-based characterization for wind pressures. J. Wind Eng. Ind. Aerodyn. 2016, 158, 162-163.

15. Kareem, A.; Tognarelli, M.A.; Gurley, K.R. Modeling and analysis of quadratic term in the wind effects on structures. J. Wind Eng. Ind. Aerodyn. 1998, 74-76, 1101-1110. [CrossRef]

16. Kareem, A.; Zhao, J. Analysis of non-Gaussian surge response of tension leg platforms under wind loads. J. Offshore Mech. Arct. Eng. 1994, 116, 137-144. [CrossRef]

17. Gurley, K.R.; Tognarelli, M.A.; Kareem, A. Analysis and simulation tools for wind engineering. Probabilistic Eng. Mech. 1997, 12, 9-31. [CrossRef]

18. Gurley, K.; Kareem, A. Analysis, interpretation, modeling and simulation of unsteady wind and pressure data. J. Wind Eng. Ind. Aerodyn. 1997, 69-71, 657-669. [CrossRef]

19. Kwon, D.; Kareem, A. Peak Factors for Non-Gaussian Load Effects Revisited. J. Struct. Eng. 2001, 137, 1611-1619. [CrossRef]

20. Sadek, F.; Simiu, E. Peak non-Gaussian wind effects for database-assisted low-rise building design. J. Eng. Mech. 2002, 128, 530-539. [CrossRef]

21. Rizzo, F.; Maddaloni, G.; Occhiuzzi, A.; Prota, A.; Pagliaroli, A. Earthquake induced floor accelerations on a High-rise building: In Scale Tests on Shaking Table. In Proceedings of the Resilient Technologies for Sustainable Infrastructures (IABSE 2020), Christchurch, New Zeeland, 2-4 September 2020.

22. Rizzo, F.; Maddaloni, G.; Occhiuzzi, A.; Prota, A. High-rise building dynamics identification through shaking table measurements on scale model for multi-hazard experiments. In Proceedings of the ANIDIS 2019, Ascoli Piceno, Italy, 15-19 September 2019.

23. Ross, I.; Altman, A. Wind tunnel blockage corrections: Review and application to Savonius vertical-axis wind turbines. J. Wind Eng. Ind. Aerodyn. 2011, 99, 523-538. [CrossRef]

24. Cook, N.J.; Mayne, J.R. A novel working approach to the assessment of wind loads for equivalent static design. J. Wind Eng. Ind. Aerodyn. 1979, 4, 149-164. [CrossRef]

25. Cook, N.J.; Mayne, J.R. A refined working approach to the assessment of wind loads for equivalent static design. J. Wind Eng. Ind. Aerodyn. 1980, 6, 125-137. [CrossRef]

26. Cook, N.J. Calibration of the quasi-static and peak-factor approaches to the assessment of wind loads against the method of Cook and Mayne. J. Wind Eng. Ind. Aerodyn. 1982, 10, 315-341. [CrossRef]

27. Cook, N.J. The Designer's Guide to Wind Loading of Building Structures; Part 1: Background, Damage Survey, Wind Data and Structural Classification; Building Research Establishment: Butterworths, UK, 1985.

28. Cook, N.J. The Designer's Guide to Wind Loading of Building Structures; Part 2: Static Structures; Building Research Establishment: Butterworths, UK, 1990.

29. Harris, R.I. An improved method for the prediction of extreme values of wind effects on simple buildings and structures. J. Wind Eng. Ind. Aerodyn. 1982, 9, 343-379. [CrossRef]

30. Tamura, Y.; Yoshida, A.; Zhang, L.; Ito, T.; Nakata, S. Examples of modal identification of structures in Japan by FDD and MRD techniques. In Proceedings of the EACWE4-The Fourth European \& African Conference on Wind Engineering; Naprstek, J., Fischer, C., Eds.; ITAM AS CR: Prague, Czech Republic, 2005.

31. Massey, F.J. The Kolmogorov-Smirnov Test for Goodness of Fit. J. Am. Stat. Assoc. 1951, 46, 68-78. [CrossRef] 